\title{
Estradiol impact on hypertension profile in obese patients
}

\author{
Juraj Jug'*, \\ DRea Levicki², \\ OInes Vinković', \\ OFilip Mustač', \\ Martina Matovinović ${ }^{3}$, \\ CLada Bradić ${ }^{3}$, \\ OMartina Lovrić \\ Benčić ${ }^{3}$
}

'University of Zagreb School of Medicine, Zagreb, Croatia

${ }^{2}$ Požega General County Hospital, Požega, Croatia

${ }^{3}$ University of Zagreb School of Medicine, University Hospital Centre Zagreb, Zagreb, Croatia

\author{
KEYWORDS: estradiol, prehypertension, obesity, hypertension. \\ CITATION: Cardiol Croat. 2019;14(9-10):234. | https://doi.org/10.15836/ccar2019.234 \\ *ADDRESS FOR CORRESPONDENCE: Juraj Jug, Klinički bolnički centar Zagreb, Kišpatićeva 12, HR-10000 Zagreb, \\ Croatia. / Phone: +385-91-5022-884 / E-mail: juraj2304@gmail.com \\ ORCID: Juraj Jug, https://orcid.org/0000-0002-3189-1518 • Rea Levicki, https://orcid.org/0000-0003-3687-1310 \\ Ines Vinković, https://orcid.org/0000-0003-1705-8295 • Filip Mustač, https://orcid.org/0000-0003-2851-6183 \\ Martina Matovinović, https://orcid.org/0000-0002-6325-7394 • Lada Bradić, https://orcid.org/0000-0001-8296-699X \\ Martina Lovrić Benčić, https://orcid.org/0000-0001-8446-6120
}

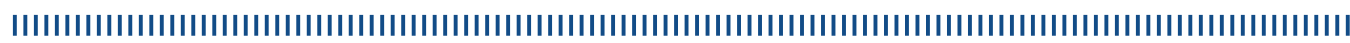

Introduction: Obesity is a well-known risk factor for developing hypertension. Prehypertensive patients (with an average $24 \mathrm{~h}$ monitored blood pressure between 120/85 and 139/89mmHg) rarely get physician's attention despite their differences from non-hypertensive patients. ${ }^{1,2}$

Patients and Methods: We enrolled 42 obese female patients (age range from 26 to 69 years) from a multidisciplinary weight management program (BMI range 30 to $49.9 \mathrm{~kg} / \mathrm{m}^{2}$ ). Firstly, because of estradiol levels, patients were divided into two groups, younger than 50 years (A) and older (B). Due to the average values of patient's ambulatory monitored blood pressure, patients were additionally put into three groups ( 1 = below $120 / 85 \mathrm{mmHg}, 2$ = between $120 / 85$ to $139 / 89 \mathrm{mmHg} 3=$ above $140 / 90 \mathrm{mmHg}$ ). Systolic dipping profile, estradiol levels, and average nocturnal heart rate were also checked.

Results: Prehypertensive obese patients older than 50 years (B) had higher nocturnal heart rate (58.50 vs. 70.25/min; $\mathrm{p}<0.05$ ) Even though differences were found in younger patients, they were not statistically significant. Systolic dipping profile was different and age-dependent (Non-dippers A: 44.00\%; B 82.35\%; $\mathrm{p}=0.02$ ). The number of non-dippers in the younger group was highest in group 2 (66\% vs. $20 \%$ in group 1; $p=0.03$ ) while there were no differences in the older group. The prehypertensive group had very similar results to hypertensive patients. Estradiol levels (Figure 1) were age independently lower in non-dippers (A: 185.5 vs. 201.07, NS; B: 71.9 vs. 87.0, NS) and also in hypertensive patients (A: 111.0 vs 192.6 pmol/L, p=0.21; B: 59.0 vs. 98.0 pmol/L).

Conclusion: Our results showed that estradiol levels seem to be protective in terms of blood pressure stability, systolic dipping profile and nocturnal heart rate probably due to its impact on autonomic nerve system functionality. Because of a small number of patients further investigation is needed to prove the statistical significance of this statement.

\section{RECEIVED:}

August 4, 2019

ACCEPTED:

September 16, 2019

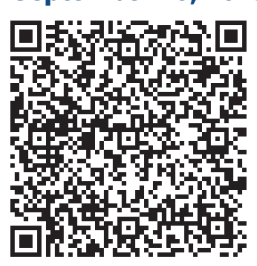

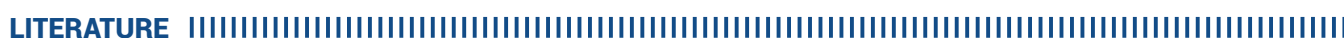

1. Mercuro G, Zoncu S, Piano D, Pilia I, Lao A, Melis GB, et al. Estradiol-17beta reduces blood pressure and restores the normal amplitude of the circadian blood pressure rhythm in postmenopausal hypertension. Am J Hypertens. 1998 Aug;11(8 Pt 1):909-13.

https://doi.org/10.1016/s0895-7061(98)00096-x

2. Egan BM, Stevens-Fabry S. Prehypertension--prevalence, health risks, and management strategies. Nat Rev Cardiol. 2015 May;12(5):289-300. https://doi.org/10.1038/nrcardio.2015.17 $\square$ Cardiologia Croatica 2019;14(9-10):234. 